ACCEPTED MANUSCRIPT

\title{
Comparison between thermophysical and tribological properties of two engine lubricant additives: Electrochemically exfoliated graphene and molybdenum disulfide nanoplatelets
}

To cite this article before publication: María Jesús García Guimarey et al 2020 Nanotechnology in press https://doi.org/10.1088/1361$\underline{6528 / a b b 7 b 1}$

\author{
Manuscript version: Accepted Manuscript \\ Accepted Manuscript is "the version of the article accepted for publication including all changes made as a result of the peer review process, \\ and which may also include the addition to the article by IOP Publishing of a header, an article ID, a cover sheet and/or an 'Accepted \\ Manuscript' watermark, but excluding any other editing, typesetting or other changes made by IOP Publishing and/or its licensors"
}

This Accepted Manuscript is @ 2020 IOP Publishing Ltd.

During the embargo period (the 12 month period from the publication of the Version of Record of this article), the Accepted Manuscript is fully protected by copyright and cannot be reused or reposted elsewhere.

As the Version of Record of this article is going to be / has been published on a subscription basis, this Accepted Manuscript is available for reuse under a CC BY-NC-ND 3.0 licence after the 12 month embargo period.

After the embargo period, everyone is permitted to use copy and redistribute this article for non-commercial purposes only, provided that they adhere to all the terms of the licence https://creativecommons.org/licences/by-nc-nd/3.0

Although reasonable endeavours have been taken to obtain all necessary permissions from third parties to include their copyrighted content within this article, their full citation and copyright line may not be present in this Accepted Manuscript version. Before using any content from this article, please refer to the Version of Record on IOPscience once published for full citation and copyright details, as permissions will likely be required. All third party content is fully copyright protected, unless specifically stated otherwise in the figure caption in the Version of Record.

View the article online for updates and enhancements. 


\section{Comparison between Thermophysical and Tribological}

\section{Properties of Two Engine Lubricant Additives:}

\section{Electrochemically Exfoliated Graphene and Molybdenum}

\section{Disulfide Nanoplatelets}

María J.G. Guimarey ${ }^{a, b^{*}}$, Amor M. Abdelkader ${ }^{\text {b,c }}$, María J.P. Comuñas ${ }^{a}$, Carmen Alvarez-Lorenzo $^{d}$, Ben Thomas ${ }^{b}$, Josefa Fernández ${ }^{\text {a }}$, Mark Hadfield

${ }^{a}$ Laboratory of Thermophysical Properties, Nafomat Group, Department of Applied Physics, Faculty of Physics, University of Santiago de Compostela, 15782, Santiago de Compostela, Spain

${ }^{\mathrm{b}}$ Department of Design and Engineering, Faculty of Science \& Technology, Bournemouth University, Poole, Dorset, BH12 5BB, United Kingdom

${ }^{c}$ Department of Engineering, University of Cambridge, Cambridge, CB3 OFS, United Kingdom

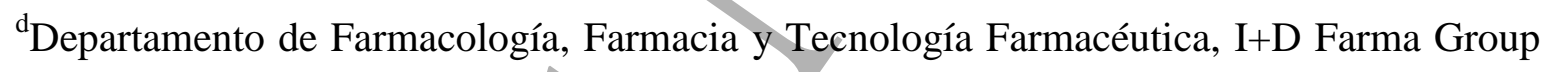
(GI-1645), Facultad de Farmacia and Health Research Institute of Santiago de Compostela (IDIS), Universidade de Santiago de Compostela, 15782, Santiago de Compostela, Spain

*Corresponding author. Tel.: +34 691890226

E-mail address: mgarciaguimarey@ bournemouth.ac.uk 


\begin{abstract}
Recently graphene and other $2 \mathrm{D}$ materials were suggested as nano additives to enhance the performance of nanolubricants and reducing friction and wear-related failures in moving mechanical parts. Nevertheless, up to our knowledge there are not previous studies on electrochemical exfoliated nanomaterials as lubricant additives. In this work, engine oil-based nanolubricants were developed via two-steps method using two different 2D nanomaterials: a carbon-based nano additive, graphene nanoplatelets (GNP) and a sulphide nanomaterial, molybdenum disulfide $\left(\mathrm{MoS}_{2}\right)$ nanoplatelets (MSNP). The influence of these nano additives on the thermophysical properties of the nanolubricants, such as viscosity index, density and wettability, was investigated. The unique features of the electrochemical exfoliated GNP and MSNP allow the formulation of nanolubricant with unusual thermophysical properties. Both the viscosity and density of the nanolubricants decreased by increasing the nanoplatelets loading. The effect of the nano additives loading and temperature on the tribological properties of nanolubricants was investigated using two different test configurations: reciprocating ball-on-plate and rotational ball-on-three-pins. The tribological specimens were analysed by Scanning Electron Microscopy (SEM) and 3D profiler in order to evaluate the wear. The results showed significant improvement in the antifriction and anti-wear properties, for the 2Dmaterials-based nanolubricants as compared with the engine oil, using different contact conditions. For the reciprocal friction tests, maximum friction and worn area reductions of $20 \%$ and $22 \%$ were achieved for the concentrations of $0.10 \mathrm{wt} \%$ and $0.20 \mathrm{wt} \% \mathrm{GNP}$, respectively. Besides, the best anti-wear performance was found for the nanolubricant containing 0.05 wt $\%$ MSNP in rotational configuration test, with reductions of $42 \%$ and $60 \%$ in the scar width and depth, respectively, with respect to the engine oil.
\end{abstract}


Keywords: Engine oil, Graphene Nanoplatelets, Molybdenum Disulfide Nanoplatelets, Tribological properties. 


\section{INTRODUCTION}

Saving fuel, emission control and increasing the engine service life are some of the main challenges facing the automotive industry [1]. In 2015, the transportation sector included about 1,600 million vehicles used for transportation of people and freight in sea, land, and air. Road vehicles used $75 \%$ of the total energy use in transportation [2, 3]. One of the main causes of greenhouse gases emission and higher fuel consumption is the engine friction. Around $28 \%$ of the fuel energy is lost due to direct frictional losses, without taking into account those caused by braking friction [4]. Due to the high pressure and temperature conditions within the combustion engine, the lubricant degrades more rapidly and loses their lubricating properties [5]. Further, by improving the antifriction and antiwear properties of the lubricants, the lifetime of the moving parts will increase, which in turn would enhance the durability of the engine. Therefore, improving the efficiency of the lubricants would bring tremendous environmental and economic benefits [6].

Friction losses take place in three main parts of the engine; the piston ring-cylinder liner interface, the crankshaft and the valve train [7]. Reducing the wear and friction losses in these engine components is linked to the use of suitable lubricating oils, which contain tailored additive packages. A wide variety of lubricant additives are available to enhance the properties of the engine oil, such as friction modifiers (FMs), which are used mainly to reduce friction losses. This type of additives improves load-carrying capability and are applied mainly on the boundary and mixed lubrication regimes [8].

Recently, nanomaterials have been widely employed as lubricant additives because of their excellent physical and chemical properties. Several researchers have reported that incorporation of nanoparticles into lubricating oil can improve their extreme pressure, antiwear and friction reduction properties [9-11]. The reduced size of nanoparticles allows them to repair defects of the contact surfaces through different mechanisms, which depend 
on the morphology and the nature of the nanoparticles, producing subsequently positive lubrication effects.

The rheological behaviour of nanolubricants depends on several characteristics of the nano additives such as the particle size, morphology and concentration. Thus, control of the variation on viscosity properties of the nanolubricants is of great interest. In particular, viscosity reduction leads to lower friction forces between the piston ring and cylinder liner [12] and achieves a decrease in fuel consumption by $0.2-2.5 \%$ [2]. Further, according to Hamrock and Dowson equation [13], lubricant film thickness depends on their viscosity. A low lubricant viscosity results in thin oil film, which leads to an increase in the surface contact and hence, the wear of sliding surfaces [14]. For this reason, nano additives are more efficient under boundary lubrication (BL) regime forming a tribofilm on the asperity contact surface. Wettability is another important property to be taken into consideration due to the influence on the tribological properties of contact surfaces at the micro and nanoscales [15]. Contact angle, one of wetting properties, plays an important role in improving tribological properties. Thus, hydrophilic surfaces (static water contact angle $<90^{\circ}$ ) have high free surface energy and hence, present a higher resistance against friction and wear [16].

All 2D materials, such as graphene nanoplatelets (GNP) and molybdenum disulfide $\left(\mathrm{MoS}_{2}\right)$ nanoplatelets (MSNP) exhibit lamellar morphology, with the atomic or molecular thick layers connected via weak van der Waals forces. The adjacent layers are readily exfoliated under a shear force, and lower friction is achieved with sliding movement [17]. For this reason, in this work GNP and MSNP were selected among other kind of nanomaterials to be analysed as lubricant additives. Different researchers have employed graphene and other 2D nanomaterials in different base oils to improve friction and wear reduction. Eswaraiah et al. [18] have observed an $80 \%$ reduction in friction coefficient for 
graphene-based engine oil without modifying the nanomaterial surface, using a four-ball tester. Lin et al. [19] have demonstrated that the addition of graphene platelets, modified by stearic and oleic acids, improves notably the wear resistance and load-carrying capacity of lubricating oils. Sulfides nanoparticles $\left(\mathrm{MoS}_{2}, \mathrm{WS}_{2}, \mathrm{CuS}\right)$ exhibit protective film mechanism as a result of heat generated for the friction between the mating surfaces [1]. Kogovšek and Kalin [20] have compared the tribological behaviour in boundary lubrication regime, using a ball-on-disc configuration, of seven different micro and nano additives in polyalphaolefin (PAO) oil: $\mathrm{MoS}_{2}$ nanotubes and platelets (2 and $\left.10 \mu \mathrm{m}\right), \mathrm{WS}_{2}$ nanotubes and fullerene-like nanoparticles, graphite platelets and multi-walled carbon nanotube. $\mathrm{MoS}_{2}$ particles (nanotubes and platelets) showed the best friction reduction (55$60 \%$ ) as compared to $\mathrm{WS}_{2}$ and carbon-based particles. Koshy et al. [21] have investigated the tribological performance of a vegetable (coconut) oil and of mineral oil (500 $\mathrm{N}$ baseoil) with $\mathrm{MoS}_{2}$ nanoparticles (unmodified and surfactant-modified) under boundary film lubrication regime. The results show that friction and wear reduction increases when nanolubricants are used at the sliding interface rather than the base lubricant. However, the majority of the work in the literature used graphene and $\mathrm{MoS}_{2}$ nanoparticles with small lateral size, which increases the edge to plane ratio. While the layers in the nanoplatelets can move relative to each other upon applying shear stress, the edges are very sharp and might cause several types of scratches and surface imperfections. In addition, most of the $\mathrm{MoS}_{2}$ in the literature have been prepared by hydrothermal processes followed by a heat treatment step. This kind of materials usually suffers from a high level of amorphous phases contamination, which is usually harder than crystalline 2D materials and could be a source of wear on the surface. Furthermore, the nanoparticles additives usually suffer from agglomeration in many oil-based system and surfactants are added to prevent the particles from clustering, which might increase the risk of corrosion. It is also important to have a 
comparative study between graphene and $\mathrm{MoS}_{2}$ based lubricants at the boundary conditions to shade more light on the tribofilm formation.

In this work, large flakes $(2-10 \mu \mathrm{m}$ lateral size) of multi-layered graphene and $\mathrm{MoS}_{2}$ prepared by cathodic electrochemical exfoliation were used as the nano additive to commercial engine oil (5W-30). The specific preparation of both materials was selected to avoid sharp edges and, consequently, scratches and surface imperfections obtained with other procedures. In addition, the residual electrostatic charges on the surface obtained whit this procedure lead to the nanoplatelets did not show any significant agglomeration without the need of surfactants. The nanolubricant prepared using both types of nanoplatelets showed considerable enhancement on the anti-wear and friction properties. The work is focused on investigating the influence of the 2D materials on the tribological properties (friction and wear) in boundary lubrication regime using different loading of the nanoplatelets. Tribological tests were performed simulating real engine sliding conditions and using different contact geometries: ball-on-plate and ball-on-three-pins.

\section{EXPERIMENTAL DETAILS}

\subsection{Nanoparticles and Engine Oil}

GNP and MSNP were obtained by the cathodic electrochemical exfoliation using DMSO-based electrolyte. The flakes are less than $20 \mathrm{~nm}$ thick, and the average lateral size is of 5 and of $2 \mu \mathrm{m}$ for graphene and for molybdenum disulphide nanoplatelet, respectively. Details on the process and materials analysis are given elsewhere [22]. Commercial SAE 5W-30 synthetic oil was used as the base oil to prepare the nanolubricants in this work. Table 1 summarises the specifications of this engine oil. 
Table 1. Properties of neat 5W-30 engine oil.

\begin{tabular}{ll}
\hline \multicolumn{2}{c}{ Neat 5W-30 oil } \\
\hline VI & 163.3 \\
$\rho_{298 \mathrm{~K}} / \mathrm{kg} \mathrm{m}^{-3}$ & 848.6 \\
$v_{303 \mathrm{~K}} / \mathrm{mm}^{2} \mathrm{~s}^{-1}$ & 112.74 \\
$v_{373 \mathrm{~K}} / \mathrm{mm}^{2} \mathrm{~s}^{-1}$ & 11.83 \\
\hline
\end{tabular}

Fourier Transform Infrared (FTIR) spectroscopy was employed to characterise the fresh 5W-30 engine oil sample and to study the formation of chemical bonds between the nano additives and the base oil. Figure 1 shows infrared spectra of the engine oil sample and the nanolubricants with the highest concentration of each nano additive, which was collected in a FTIR spectrometer (VARIAN 670-IR) equipped with a Golden Gate horizontal attenuated total reflectance (ATR) accessory in transmission mode and over the spectral range $4000-400 \mathrm{~cm}^{-1}$. FTIR spectrum shows in the range between 3000 and 2850 $\mathrm{cm}^{-1}$ typical bands of C-H stretching, in particular at 2920 and $2852 \mathrm{~cm}^{-1}$ which conform to $-\mathrm{CH}_{2}$ asymmetrical and symmetrical stretching, respectively. The peak at $1460 \mathrm{~cm}^{-1}$ corresponds to $-\mathrm{CH}_{2}$ scissoring. In addition to $\mathrm{C}-\mathrm{H}$ stretching peaks, methyl groups exhibit $\mathrm{C}-\mathrm{H}$ bend at $1375 \pm 10 \mathrm{~cm}^{-1}$ [23]. This peak is clearly seen in Figure 1 at $1377 \mathrm{~cm}^{-1}$, which confirms the presence of symmetric $-\mathrm{CH}_{3}$ bending. The last peak takes place at $721 \mathrm{~cm}^{-1}$ that corresponds at $-\mathrm{CH}_{2}$ rocking vibration. This band is observed only in long-chain alkanes (with at least four methylene groups in a row). No new spectral peaks or shifts are found for the nanolubricants compared to the engine base oil, which indicates that no chemical bonds were formed. 

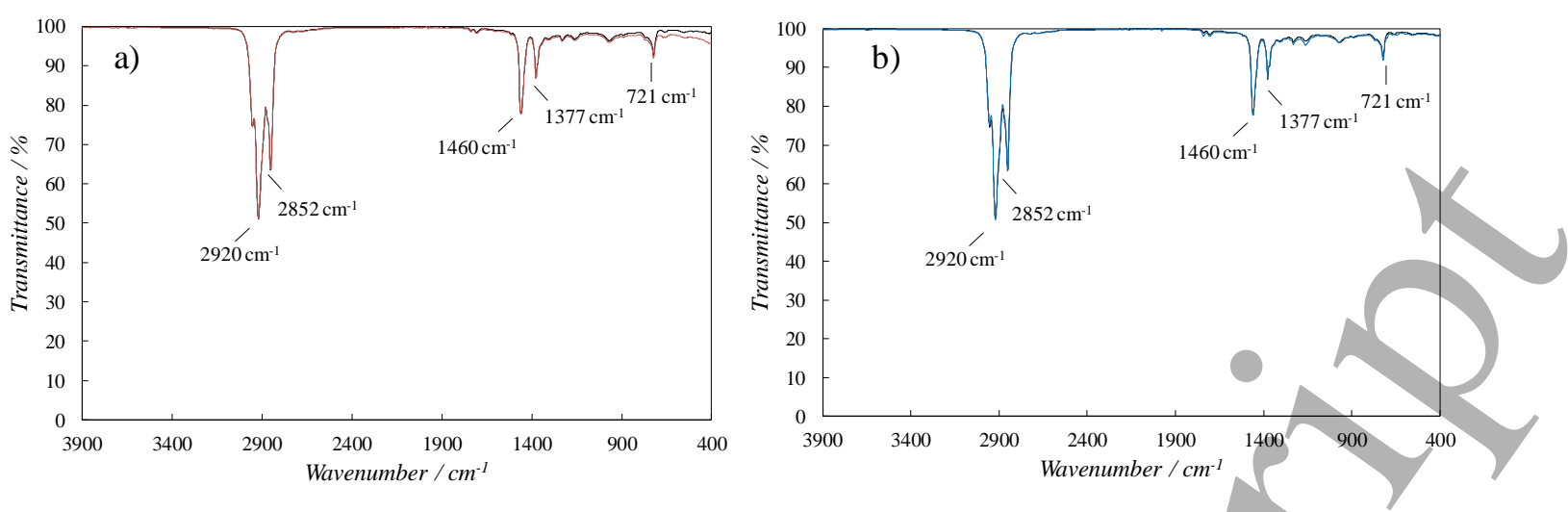

Figure 1. FTIR spectrum of engine oil SAE 5W-30 (black line) and nanolubricants with $0.20 \mathrm{wt} \%$ of a) GNP (red line) and b) MSNP (blue line).

The FTIR spectrum of the engine oil corresponds to a polyalphaolefin (PAO) [24]. PAOs are mainly used as high-performance functional base fluids in engine lubricants. These synthetic lubricants are classified by their kinematic viscosities at $373.15 \mathrm{~K}$. Therefore; the engine oil $5 \mathrm{~W}-30$ can be associated as PAO12 because it has a kinematic viscosity of $11.83 \mathrm{~mm}^{2} \mathrm{~s}^{-1}$ at $373.15 \mathrm{~K}$.

\subsection{Formulation of nanolubricants}

Three different concentrations of both nano additives were prepared by the two-step method: $0.05 \mathrm{wt} \%, 0.10 \mathrm{wt} \%$ and $0.20 \mathrm{wt} \%$. The weight fractions used have been selected with the criterion of cost reduction for a future industrial application. The use of small quantities reduces the manufacturing cost of the nanolubricant. Furthermore, previous works $[25,26]$ have shown that the use of weight fractions greater causes a decrease in the antifriction and anti-wear capacity of the nanolubricant and reduces its stability. But on the contrary, Gupta et al. [27] have concluded that if the nanoparticle concentration is sufficiently low, the lubrication is ineffective and friction/wear is dominated by base oil. Therefore, there is no concrete evidence on the optimum concentration of nano additives to be used because their effectiveness depends on certain factors, such as their compatibility with base oils, their size and morphology and their dispersion stability. The appropriate 
amount of GNP and MSNP was added to $100 \mathrm{~mL}$ of the motor oil $5 \mathrm{~W}-30$ and was stirred with an ultrasonic bath (Ultrawave $\mathrm{U} 500 \mathrm{H}$ ) for 8 hours at a $44 \mathrm{kHz}$ frequency to obtain a uniform dispersion. The procedure used for nanolubricants preparation is shown in schematic Figure 2.

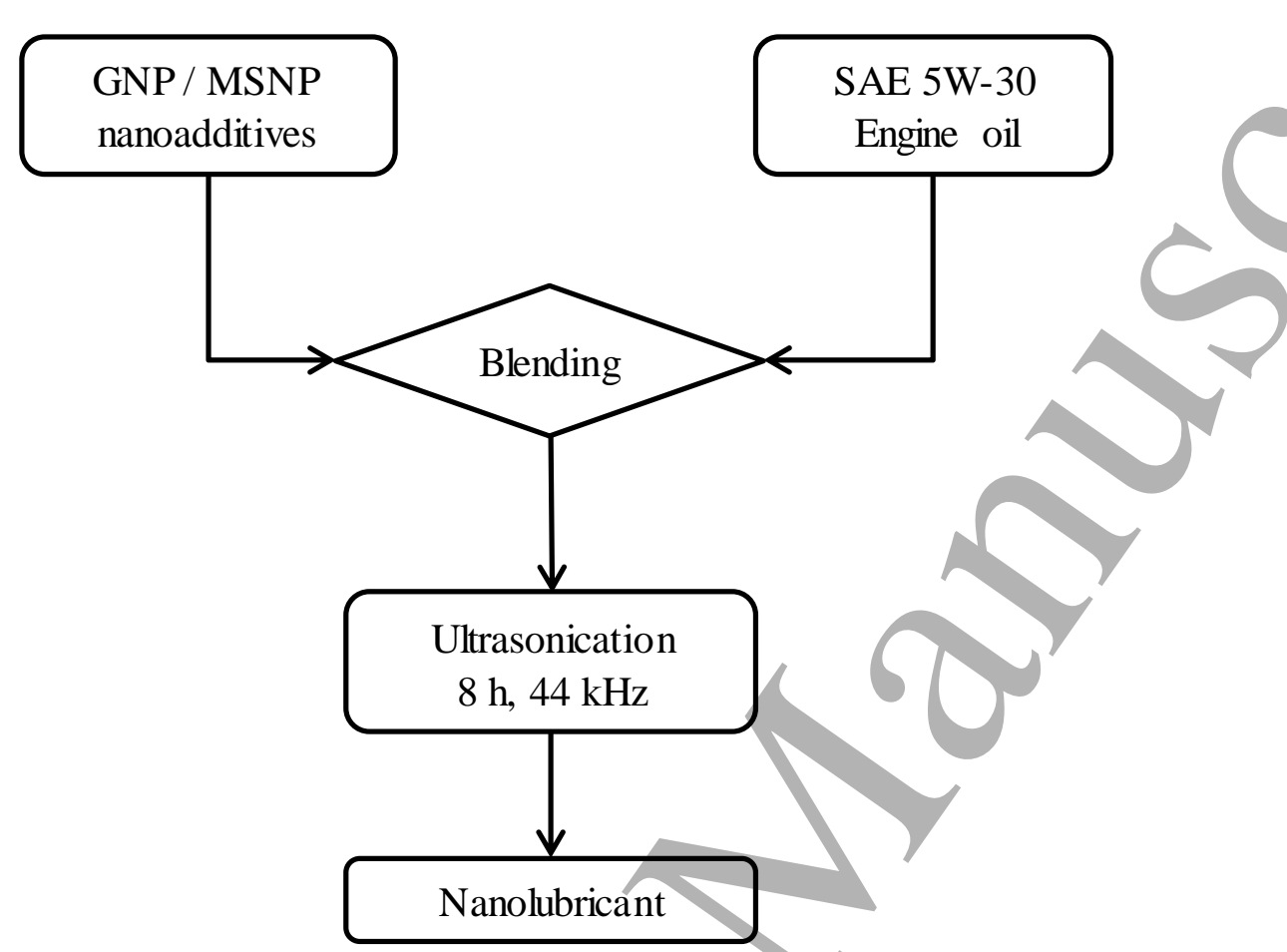

Figure 2. The procedure used for nanolubricant preparation.

\subsection{Nanolubricants stability}

The stability of the nanolubricants was evaluated by two different methods: visual control and temporal evolution of the refractive index. The first method consists of taking photographs of the nanolubricants over time from the moment they are prepared. The second method is based on measuring the refractive index of the base oil and the nanolubricants and observing how it varies as a function of time. A Mettler Toledo RA-510 $M$ refractometer was used to register the temporal evolution of the refractive index (n) at T $=296.15 \mathrm{~K}$ operating at the wavelength of the D-line of sodium $(589.3 \mathrm{~nm})$. This apparatus works in a range from 1.32 to 1.56 with a resolution of 0.00001 . The nanolubricants with 
the highest load with each type of nanoparticle have been selected to carry out the stability study, thus ensuring that the stability for lower concentrations will be equal or greater. This method was presented in our previous works [24, 28].

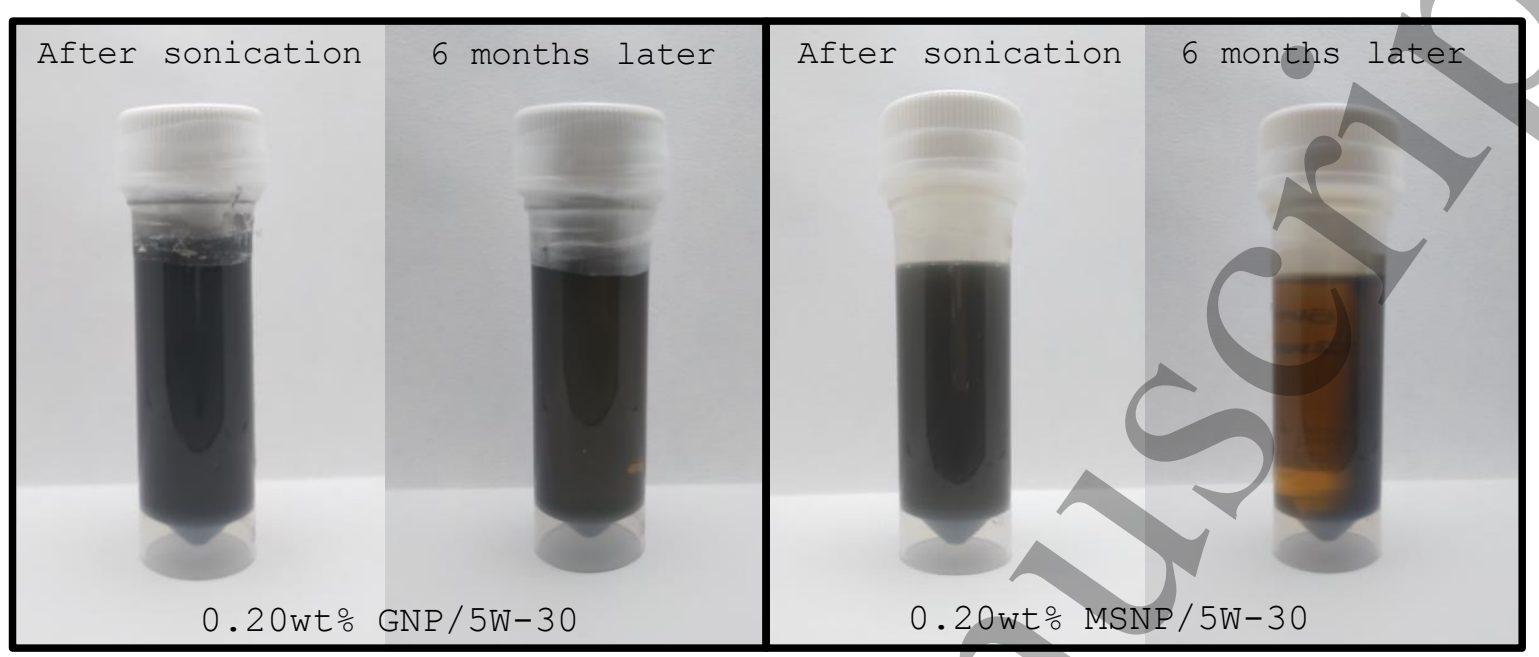

Figure 3. Digital images of the just prepared nanolubricants with the highest nanoparticle loading and after 6 months of the preparation.

Figure 3 shows digital images of the nanolubricants with a concentration of 0.20 wt $\%$ after different periods of preparation. A slight sedimentation is observed in the nanolubricant containing MSNP as nano additive. However, the sedimentation at the bottom of the bottle is negligible with GNP nano additive material. This indicates less stability for the nanolubricant containing MSNP. The temporal evolution of the refractive index can be observed in Figure 4. An overall refractive index variation of 0.008 and 0.003 over $96 \mathrm{~h}$ was obtained for $0.20 \mathrm{wt} \% \mathrm{MNSP}$ and for $0.20 \mathrm{wt} \%$ GNP nanolubricants, respectively. The overall variation of the refractive index is smooth $(\leq 0.003)$ during the 96 first hours after sonication for GNP-based nanolubricant while this variation (0.003) is reached at 15 hours for the MSNP-based nanolubricant. A better stability for the nanolubricant of $0.20 \mathrm{wt} \%$ of GNP is again verified. These results reveal that these nanolubricants are stable during this time interval without using any surfactant. 


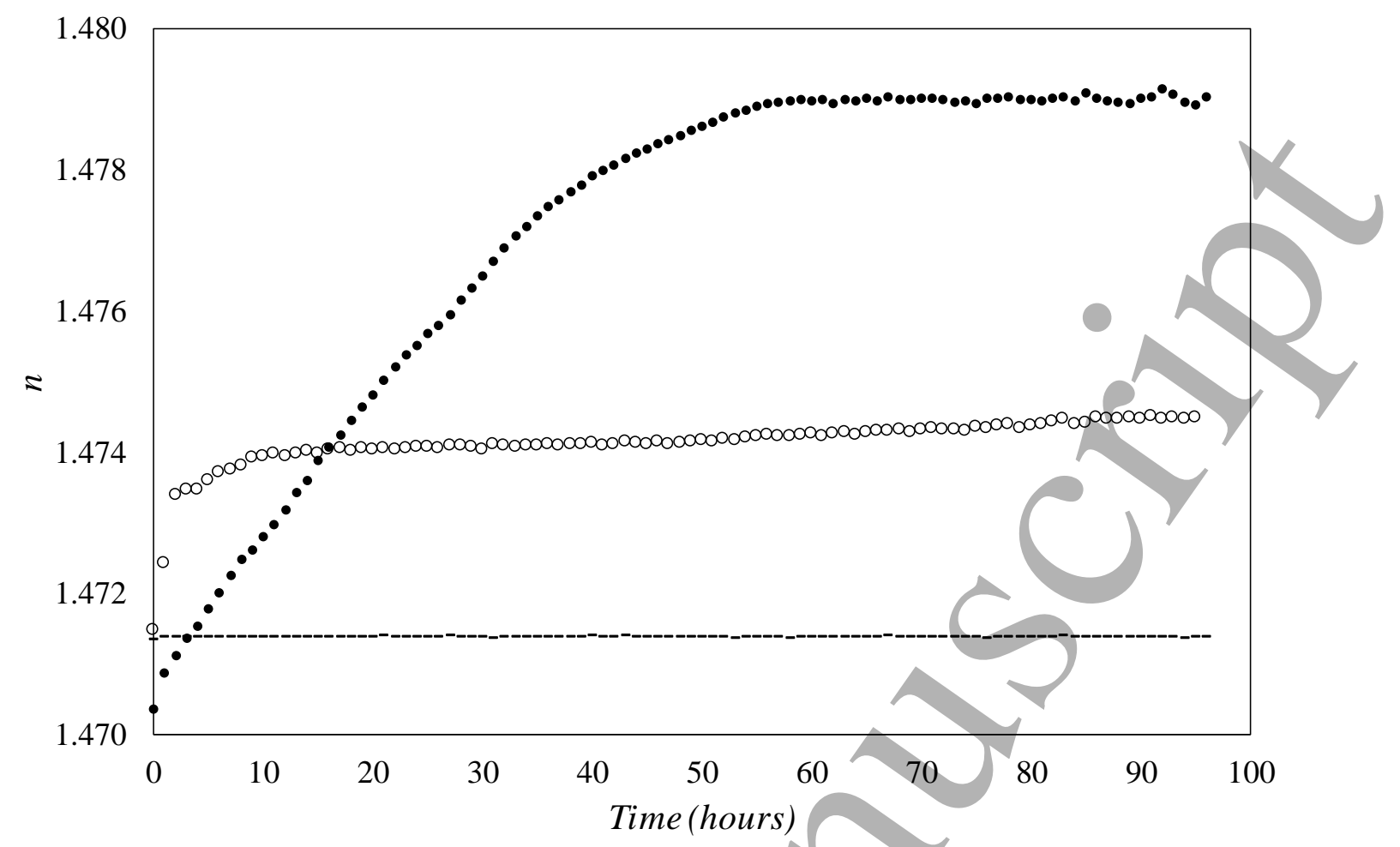

Figure 4. Temporal evolution of the refractive index, $\mathrm{n}$, at $\mathrm{T}=296.15 \mathrm{~K}$ for base oil, $5 \mathrm{~W}$ 30 (broken line), and for nanolubricants at 0,20 wt $\%$ GNP (unfilled circle) and $0.20 \mathrm{wt} \%$ MSNP (filled circle).

\subsection{Characterisation of nanolubricants}

\subsubsection{Wettability}

The wetting behaviour of the neat engine oil and the nanolubricants was evaluated using a contact angle analyser (Phoenix MT) at ambient temperature ( 296 K). Before the contact angle, $\theta$, measurements, the surfaces used for the tribological tests (AISI 420 stainless steel plate) were rinsed with ethanol and dried in a stream of hot air. To measure the static contact angle, $1 \mathrm{ml}$ of lubricant sample was dropped on the sample surface using a syringe. At least three measurements of the contact angle were replicated, and the average value of the steady-state value and its standard deviation was calculated. A time period of about $30 \mathrm{~s}$ was necessary to reach a stable contact angle value with the lubricants. 


\subsubsection{Density, viscosity and viscosity index}

The thermophysical properties (density, viscosity and viscosity index) of the nanolubricants were determined with a SVM 3000 Anton Paar rotational Stabinger viscometer. This device has been described in detail previously [29]. Density and viscosity were determined over the temperature range from 278.15 to $373.15 \mathrm{~K}$ at atmospheric pressure. The temperature of the cell is controlled through an integrated thermostat with cascaded Peltier elements and measured with a Pt100 thermometer. Density cell consists of a glass U-tube, which is excited to produce mechanical resonant vibrations according to DIN 51757 standard. The expanded uncertainties $(k=2)$ are $0.02 \mathrm{~K}$ for the temperature, $T$, $0.0005 \mathrm{~g} \mathrm{~cm}^{-3}$ for density, $\rho$, and $1 \%$ in the case of dynamíc viscosity, $\eta$. This apparatus (SVM 3000) also allows measurement of the viscosity index, VI, according to the ASTM D2270 standard [30].

\subsubsection{Tribological tests}

The tribological characterisation was performed using two different contact configuration testers: a reciprocating tribometer in a ball-on-plate configuration at the starting temperature of lubricant in the engines (room temperature) and a rotational tribological cell in a ball-on-three-pins configuration at the optimum temperature of the combustion engine $(363.15 \mathrm{~K})$. Before and after each tribological test, all specimens were cleaned with hexane and dried with a stream of air for a few seconds.

Reciprocating friction tests were carried out with a CSM Standard tribometer. Chrome steel balls AISI 52100 (diameter: 6 mm; hardness: 803 HV, Young's modulus: 190 to $210 \mathrm{GPa}$; Poisson's ratio: 0.29; roughness: $32 \mathrm{~nm}$ ) were run against AISI 420 stainless steel plates $\left(40.5 \times 21 \times 5 \mathrm{~mm}^{3}\right.$; hardness: $194 \mathrm{HV}$, Young's modulus: 190 to $210 \mathrm{GPa}$; Poisson's ratio: 0.27) with a mirror finish polishing (roughness $10.55 \mathrm{~nm}$ ). The plates were lubricated with five drops of the neat oil $(5 \mathrm{~W}-30)$ or the nanolubricants. The 
setup used in the tests is shown in Figure 5(a). Tests were conducted at room temperature ( $296 \mathrm{~K})$ under normal load of $20 \mathrm{~N}$, which correspond to maximum Hertzian contact pressures of 1.8 GPa. At least three replicates were performed for each sample at a stroke length of $10 \mathrm{~mm}$, sliding a total distance of $360 \mathrm{~m}$ with an average sliding speed of 0.064 $\mathrm{m} \mathrm{s}^{-1}$, so the friction coefficient reported is an average of three measurements. The criterion considered for selecting values was that the difference in the friction coefficient of a test compared to the mean value should be below $15 \%$ [31]. The reciprocating friction tests have been carried out at room temperature to simulate the conditions of an internal combustion engine during start-up.

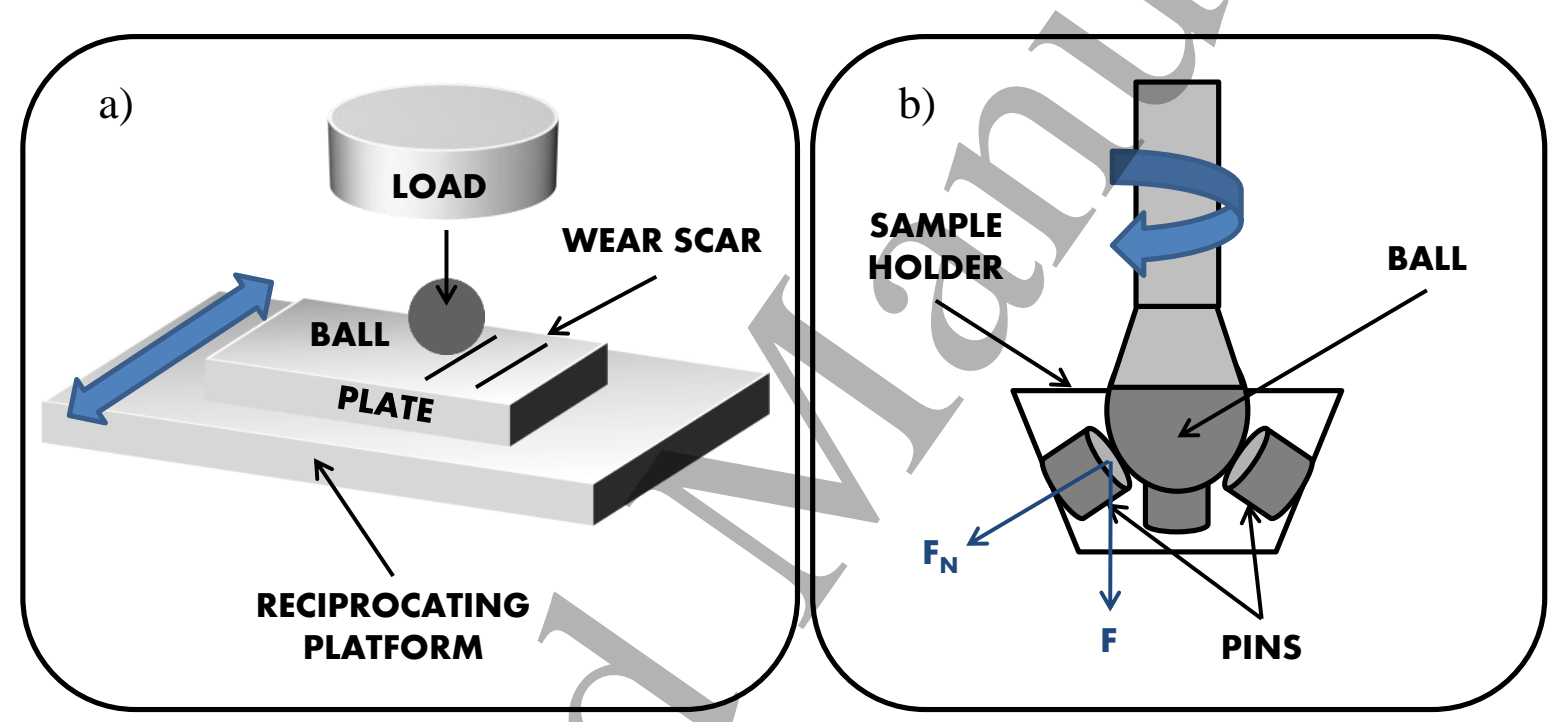

Figure 5. Schematic setup of the contact configurations employed: a) reciprocating ballon-plate and b) rotating ball-on-three-pins.

Rotational tests of the friction coefficient were performed using an Anton Paar MCR 302 rheometer equipped with a Peltier heated tribology cell T-PTD200 and a Peltier Hood H-PTD200 for precise temperature control $[32,33]$. The setup used in the tests was a ball-on-three-pins, as shown in Figure 5(b). A chrome steel ball AISI 52100 (diameter: $12.7 \mathrm{~mm}$ ) rotates against three $100 \mathrm{Cr} 6$ pins (diameter: $6 \mathrm{~mm}$ ) under an axial force $\mathrm{F}$ of 20 $\mathrm{N}$ which is transferred into three normal tribological forces $\mathrm{F}_{\mathrm{N}}$ of $9.43 \mathrm{~N}(1.1 \mathrm{GPa}$ of maximum Hertzian contact pressure) acting perpendicular to the bottom pins at the contact 
points. Both material pairings for tribological testing (ball and pins) have the following specifications: hardness from 62 to 66 Rockwell C; Young's modulus from 190 to 210 $\mathrm{GPa}$; Poisson's ratio of 0.29 and surface roughness of $0.1 \mu \mathrm{m}$. To cover the pins $0.5 \mathrm{ml}$ of the engine oil or of the nanolubricants were introduced in the sample holder. The sample holder is fitted with a protector to prevent lubricant spillage or leakage during the experiments. Two replicates were performed for each sample at a sliding distance of $180 \mathrm{~m}$ and a linear speed at the contact points of $0.1 \mathrm{~m} \mathrm{~s}^{-1}$ (rotational speed $213 \mathrm{rpm}$ ). In order to simulate the actual conditions of an internal combustion engine, an optimum operating temperature of $363.15 \mathrm{~K}$ has been selected for the rotational friction tests [5].

\subsubsection{Wear and roughness determination}

The wear produced on the discs after the tribological test was determined with a non-contact 3D Optical Profiler Sensofar S Neox working in confocal mode and with a magnification objective of $10 \mathrm{X}$ for the lower specimens (plates and pins). For upper specimens (balls), focus variation mode with a magnification objective of $20 \mathrm{X}$ was used. In the reciprocating friction tests (three replicates for sample), the counter-pairs selected to determine the wear produced were those with a COF closer to average. Profiles of the wear tracks produced in the lower specimens (plates and pins) due to the friction tests for the studied nanolubricants and $5 \mathrm{~W}-30$ engine oil were obtained using a SensoMap software. From the profile of the wear scars, wear track width (WTW), wear track depth (WTD), and cross-section area of each worn scar were analysed in three different zones in order to obtain representative average values. For the upper specimens (balls) the profile of the wear tracks could not be determined rigorously due to the spherical shape of the counterpairs. For this reason, it was only possible to determine the WTW for the balls. Furthermore, this equipment was also employed to determine the roughness surface, $R_{a}$, inside the worn scars; according to with the ISO 4287 standard and applying a Gaussian 
filter with a long wavelength cut-off of $0.08 \mathrm{~mm}$ and $0.025 \mathrm{~mm}$ for stainless steel plates and for chrome steel pins, respectively. Finally, Scanning Electron Microscopy (SEM) analyses were conducted on the worn surfaces to examine its morphology. These analyses were performed using a Carl Zeiss FESEM ULTRA Plus microscope.

\section{RESULTS AND DISCUSSION}

\subsection{Thermophysical Characterisation}

Wettability behaviour of the neat engine oil and of the nanolubricants with a concentration of $0.10 \mathrm{wt} \%$ of GNP or of MSNP was determined on the surface of the stainless steel plates (AISI 420). Average static contact angle, $\theta$, values obtained with Phoenix MT analyser and their corresponding standard deviations, $\sigma$, are presented in Table 2. SAE 5W-30 showed excellent wetting behaviour on AISI 420 stainless steel surfaces with a contact angle of $18.8^{\circ}$. This value is coherent with those obtained for PAO4 and PAO9 by Kalin et al. [34]. The static contact angle increases by $42.5 \%$ and $50.5 \%$ with respect to the neat engine oil when $0.10 \mathrm{wt} \%$ of GNP or of MSNP are added, respectively. The wettability of a surface increases as the contact angle formed by the sample deposited on is lower. Improved wetting provokes sliding at the solid-liquid interface, and therefore this fact is even more relevant in tribological applications in boundary lubrication regimes because of the direct contact between the surfaces. GNP and MSNP are intrinsically mildly hydrophilic, but 2D materials are susceptible to spontaneous hydrocarbon contamination, which reduce the surface energy and exhibit their traditionally reported hydrophobicity [35]. The hydrophobic acquired behaviour of graphene and molybdenum disulfide [36] may be one of the causes of increased contact angle when this nano additive is added to the neat oil. 
Table 2. Steady-state average values of contact angles, $\theta$, and their standard deviation, $\sigma$, values on AISI 420 stainless steel plates wetted with the neat oil and two nanolubricants.

\begin{tabular}{lll}
\hline Sample & $\boldsymbol{\theta} /{ }^{\circ}$ & $\sigma /^{\circ}$ \\
\hline Neat 5W-30 oil & 18.8 & 0.4 \\
$99.9 \mathrm{wt} \%$ 5W-30 + 0.1 wt\% GNP & 26.8 & 0.7 \\
$99.9 \mathrm{wt} \%$ 5W-30 + 0.1 wt\% MSNP & 28.3 & 2.1 \\
\hline
\end{tabular}

Experimental density and kinematic viscosity measurements for the/engine oil and for the six nanolubricants formulated with different nanoplatelets loading were conducted using a rotational Stabinger viscometer and are collected in Table S1 and Table S2 of the supplementary information. The density of nanolubricants is lower than the density of the neat oil over all the temperature range, except for the highest graphene loading $(0.20 \mathrm{wt} \%)$. These results are different from those previously published for other nanolubricants [37, 38], where the density of the nanolubricants increases with the nano additives loading due to the agglomeration of the nanoparticles. In the current work, the nanoplatelets were produced by the cathodic exfoliation processes, and the produced particles are likely to have some static charge residues on the surface [39, 40]. These static charges cause repulsive interactions between the nanoplatelets, which reduce their tendency to agglomerate [41].

The kinematic viscosity measurements showed similar behaviour to that of the density, with lower values recorded for the oil (5W-30) doped with GNP and MSNP. Several publications $[38,42,43]$ reported the increase of the viscosity of the oil with increasing the loading of the nanoparticles, which was attributed to the increasing tendency of the nanoparticles to agglomerate at high loading. This agglomeration leads to an increase in the internal shear stress in nanolubricant, and thus increases the viscosity. In the present work, the well-dispersed GNP and MSNP keep a layer of the oil on the surface, and consequently between the neighbours' flakes. Therefore, the oil works as a localised 
lubricant that facilitates the sliding of the neighbours flakes on each other upon applying any shear force. In addition, the weak van der Waals forces between the layers in the GNP and MSNP can be easily broken by the shear stress, which also lead to the layers sliding on each other and lowering the viscosity. Ali et al. [44] have observed similar behaviour of the kinematic viscosity of another 5W-30 engine oil doped with $\mathrm{Al}_{2} \mathrm{O}_{3}, \mathrm{TiO}_{2}$ and $\mathrm{Al}_{2} \mathrm{O}_{3} / \mathrm{TiO}_{2}$ nanoparticles at the temperatures of $313.15 \mathrm{~K}$ and $373.15 \mathrm{~K}$. These authors attributed the slight decrease of the viscosity with respect to neat engine oil to the nanoparticles located between the oil layers promote the relative movement between the lubricant layers [9]. Nanolubricant of SAE 20 W50 engine oil doped with multi-walled carbon nanotubes at $0.1 \mathrm{wt} \%$ showed similar behaviour [45]. The MSNP nanolubricant shows deeper viscosity variation than the GNP nanolubricant at same particle mass fractions. This phenomenon can be explained by the rougher surface and the zigzag morphology of the surface of the $\mathrm{MoS}_{2} 2 \mathrm{D}$ crystal. The kinematic viscosity of the engine oil and of the nanolubricants decreased with increasing the temperature, at moderated temperature. Some diversion was observed for the lubricants with high graphene loading, where the viscosity increased above $343.15 \mathrm{~K}$. 


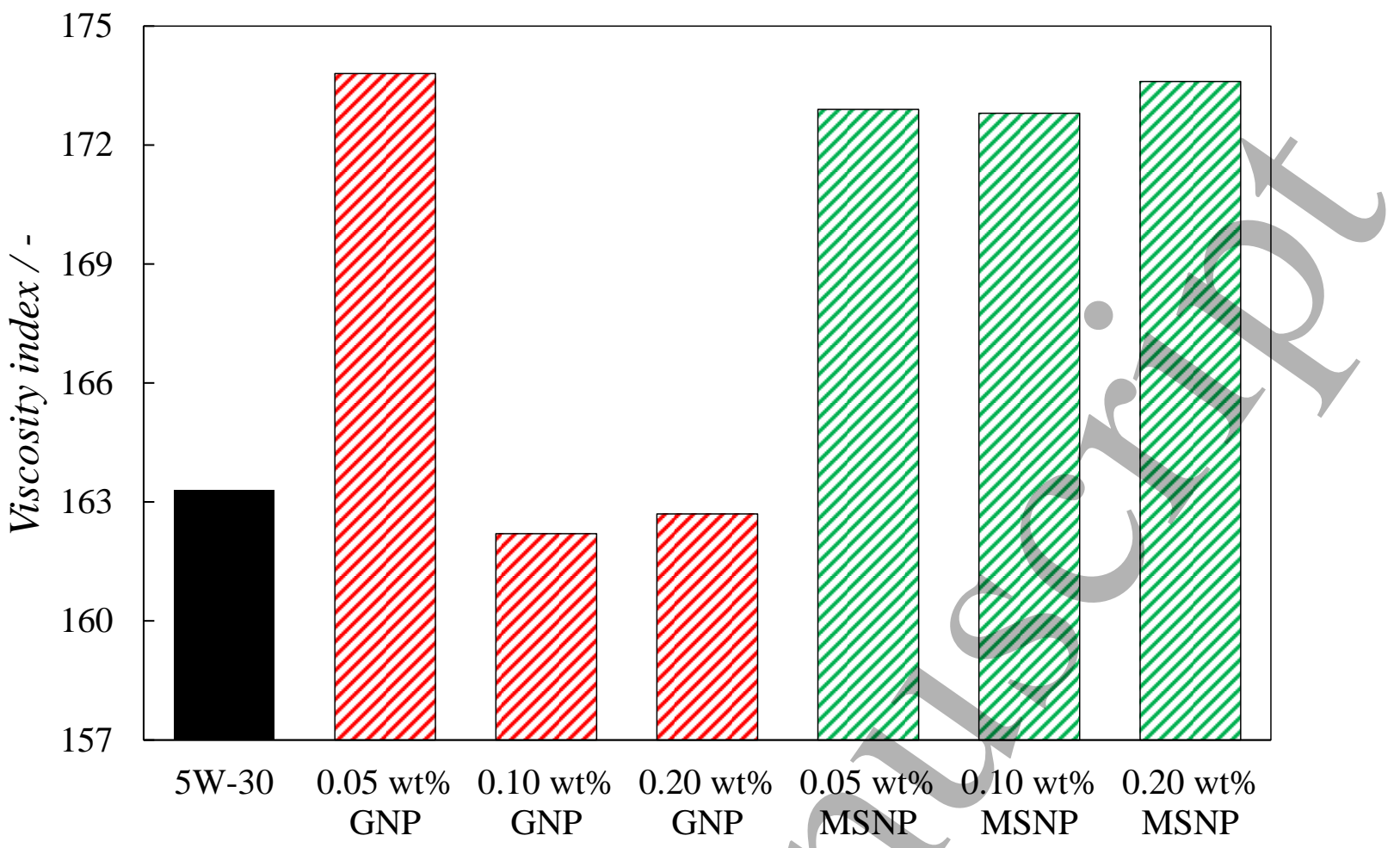

Figure 6. Viscosity index, VI, for all the nanolubricants based on 5W-30 engine oil.

The viscosity index, VI, of the GNP and MSNP-doped 5W-30 nanolubricants is plotted in Figure 6. The results show that VI increased by $6.4 \%$ for the 0.05 wt $\%$ GNP loading, and decreased for the higher loading by $0.7 \%$ and $0.4 \%$ for the $0.10 \mathrm{wt} \%$ and 0.20 wt\% loading respectively, as compared with the neat engine oil. Whereas, for the MSNP nanolubricants at $0.05 \mathrm{wt} \%, 0.10 \mathrm{wt} \%$ and $0.20 \mathrm{wt} \%$ the VI increases by $5.9 \%, 5.8 \%$ and $6.3 \%$, respectively. For GNP at 0.1 wt $\%$ a deep dip in the VI can be observed. Similar phenomenon has been observed in our previous work with PAO6/GNP nanolubricant, also at $0.1 \mathrm{wt} \%$ GNP loading [24]. This fact may be because VI is determined from the kinematic viscosities, $v$, at $313.15 \mathrm{~K}$ and $373.15 \mathrm{~K}$. At the higher temperature the $v$ values are quite close: 11.99 and $11.74 \mathrm{~mm}^{2} \mathrm{~s}^{-1}$ respectively for $0.05 \mathrm{wt} \%$ and $0.10 \mathrm{wt} \%$, whereas at $313.15 \mathrm{~K}$ the $\nu$ values are quite different: 68.74 and $71.01 \mathrm{~mm}^{2} \mathrm{~s}^{-1}$ respectively for 0.05 $\mathrm{wt} \%$ and $0.10 \mathrm{wt} \%$. The increase in the viscosity index means that the lubricant viscosity is less sensitive to temperature, resulting in lower frictional and pumping losses and therefore 
providing better resistance to lubricant film thinning and fuel efficiency in an automotive engine [46].

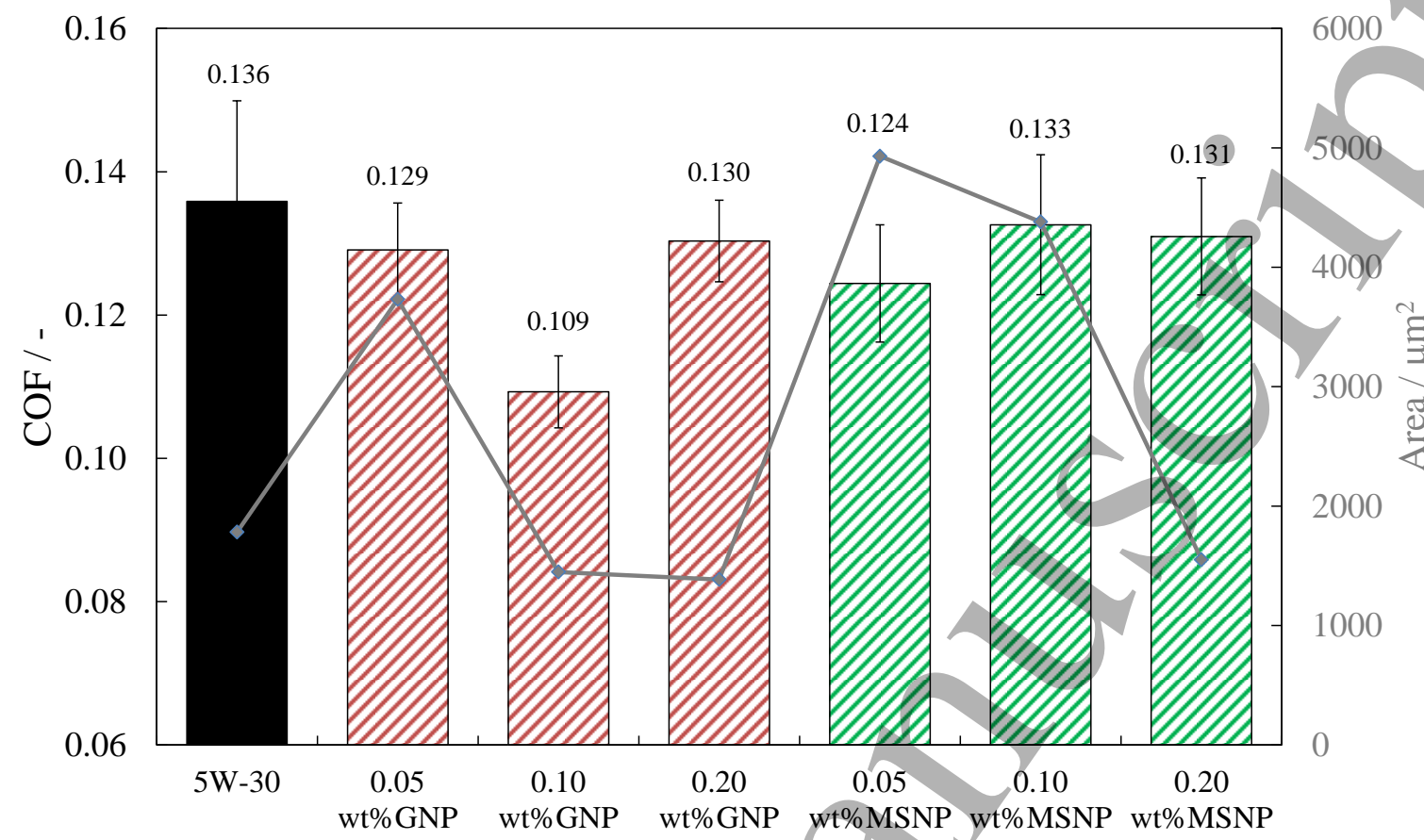

Figure 7. Coefficient of friction $(\mathrm{COF})$ and cross-section area of wear scars on plates surfaces for engine oil and six different nanolubricants at room temperature.

\subsection{Tribological Characterisation}

In order to evaluate the tribological performance of the engine oil doped with GNP and MSNP, the frictional behaviour was studied using a CSM Standard tribometer. The measured COF of nanolubricants with different GNP and MSNP loading is shown in Figure 7. Lubrication regime was determined through Eq. 1 (supplementary information) for reciprocating configuration obtaining an $\lambda$ value of 0.7 at the operating conditions, which corresponds to boundary lubrication regime. Figure 7 shows that the addition of both GNP and MSNP has a positive antifriction effect. The nanolubricant with $0.10 \mathrm{wt} \%$ GNP shows a higher reduction in friction under a load of $20 \mathrm{~N}$ and boundary conditions, reaching an improvement up 20\% when compared with neat commercial engine oil. 
The friction coefficient as a function of the sliding distance measured at $20 \mathrm{~N}$ and at $363.15 \mathrm{~K}$ in rotational frictional tests is shown in Figure S1 (supplementary information). These contact configuration tests were also carried out in boundary lubrication regime, with an $\lambda$ value of 0.06 . There is a noticeable improvement in the COF of the engine oil when doped with nano additives. The friction coefficients of the lubricants fluctuated during the first $50 \mathrm{~m}$ of the test. It can be seen that there is a slight initial decrease in COF followed by a gradual increase to a stable value after large sliding distance. This phenomenon is more pronounced for the nanolubricant with $0.10 \mathrm{wt} \%$ of MSNP, which is also the dispersion that shows the better antifriction behaviour with respect to the neat commercial engine oil (5.9\% of average COF reduction) in these tests. The decline of the COF is probably due to the high surface energy of $\mathrm{MoS}_{2}$ nanoplatelets that can easily interact and form an abrasion-resistant protective film at the contact interfaces [41]. By comparing different loading of GNP nanoparticles (Figure S1), it can be concluded that tribological performance is negatively influenced by increasing the concentration of GNP above $0.05 \mathrm{wt} \%$. The better tribological performance of the low GNP loading is due to the slightly enhanced dispersibility of graphene nanoplatelets in the base oil, which enhances the strength of tribofilm [47]. Furthermore, this behaviour agrees with the results of the viscosity index for GNP-based nanolubricants, in which an increase in VI was observed only for the lowest GNP concentration. This increase confers greater viscous stability against temperature variations and hence, allows the nanoparticles to develop a more effective lubrication mechanism. In general, $\mathrm{MoS}_{2}$ nanoplatelets show more pronounce friction reduction comparing with GNP due to shearing of the nanoparticles forming a low friction tribofilm. 


\subsection{Wear surface characterisation}

The wear of the ball surfaces and wear tracks on the plates and pins of the samples after tribological testing have been studied using optical profiling to assess the wear properties of GNP and MSNP nanolubricants. For each specific loading of the nanolubricant, three sets of data have been taken for the measurement of WTW, WTD and cross-section area and the average of three readings are gathered in Table 3 and Table 4.

Table 3. Mean values of the width, WTW, depth, WTD, cross-section area and roughness, $R_{a}$, of the wear track and their respective standard deviations, $\sigma$, for the six nanolubricants and SAE 5W-30 oil obtained for both specimens with CSM Standard tribometer at room temperature.

\begin{tabular}{|c|c|c|c|c|c|c|c|c|c|c|}
\hline \multirow{2}{*}{ Sample } & \multicolumn{7}{|c|}{ Stainless Steel plate } & \multicolumn{3}{|c|}{$\begin{array}{c}\text { Chrome } \\
\text { Steel ball }\end{array}$} \\
\hline & $\begin{array}{c}\text { WTW } \\
/ \mu \mathrm{m}\end{array}$ & $\underset{/ \mu \mathrm{m}}{\sigma}$ & $\begin{array}{l}\text { WTD } \\
/ \mu \mathrm{m}\end{array}$ & $\begin{array}{c}\sigma \\
/ \mu \mathbf{m}\end{array}$ & $\begin{array}{l}\text { Area } \\
/ \mu \mathbf{m}^{2}\end{array}$ & $/ \mu \mathrm{m}^{2}$ & $/ \mu \mathrm{m}$ & $\begin{array}{c}\sigma \\
/ \mu \mathrm{m}\end{array}$ & $\begin{array}{c}\text { WTW } \\
/ \mu \mathrm{m}\end{array}$ & $\begin{array}{c}\sigma \\
/ \mu \mathrm{m}\end{array}$ \\
\hline $5 W-30$ & 429 & 13 & 6.31 & 0.20 & 1780 & 48 & 0.093 & 0.005 & 425 & 2 \\
\hline $0.05 w t \%$ GNP & 536 & 5 & 10.74 & 0.04 & 373 & 85 & 0.094 & 0.002 & 532 & 5 \\
\hline $0.10 w t \%$ GNP & 399 & 6 & 5.54 & 0.10 & 1450 & 48 & 0.036 & 0.001 & 447 & 3 \\
\hline $0.20 \mathrm{wt} \%$ GNP & 408 & 6 & 5.43 & & 1380 & 44 & 0.060 & 0.004 & 396 & 2 \\
\hline $0.05 w t \%$ MSNP & 574 & 9 & 12.83 & & 102 & 240 & 0.144 & 0.013 & 567 & 5 \\
\hline $0.10 w t \%$ MSNP & 565 & 8 & 11.4 & & 438 & 240 & 0.080 & 0.004 & 536 & 5 \\
\hline $0.20 \mathrm{wt} \% \mathrm{MSNP}$ & 415 & 10 & 5.72 & 0.3 & 1550 & 150 & 0.056 & 0.004 & 417 & 2 \\
\hline
\end{tabular}

Table 4. Average values of the width, WTW, depth, WTD and roughness, $R_{a}$, of the wear track and their respective standard deviations, $\sigma$, obtained during rotational frictional tests at $363.15 \mathrm{~K}$ for both specimens.

\begin{tabular}{|c|c|c|c|c|c|c|c|c|}
\hline \multirow{2}{*}{ Sample } & \multirow{2}{*}{$\mathrm{WTW} / \mu \mathrm{m}$} & \multicolumn{3}{|c|}{ Chrome Steel pin } & \multirow[b]{2}{*}{$\boldsymbol{R}_{a} / \mu \mathbf{m}$} & \multirow[b]{2}{*}{$\sigma / \mu \mathrm{m}$} & \multicolumn{2}{|c|}{$\begin{array}{c}\begin{array}{c}\text { Chrome Steel } \\
\text { ball }\end{array} \\
\end{array}$} \\
\hline & & $\sigma \mu \mathrm{m}$ & $\mathrm{WTD} / \mu \mathrm{m}$ & $\sigma \mu \mathrm{m}$ & & & $\mathrm{WTW} / \mu \mathrm{m}$ & $\sigma \mu \mathrm{m}$ \\
\hline SAE 5W-30 & 256 & 6 & 0.82 & 0.07 & 0.046 & 0.001 & 198 & 3 \\
\hline $0.05 w t \%$ GNP & 160 & 15 & 0.49 & 0.01 & 0.023 & 0.003 & 188 & 2 \\
\hline $0.10 \mathrm{wt} \%$ GNP & 171 & 9 & 0.37 & 0.03 & 0.025 & 0.005 & 200 & 3 \\
\hline $0.20 \mathrm{wt} \% \mathrm{GNP}$ & 158 & 3 & 0.43 & 0.04 & 0.033 & 0.006 & 188 & 1 \\
\hline $0.05 w t \%$ MSNP & 149 & 9 & 0.33 & 0.09 & 0.026 & 0.001 & 188 & 2 \\
\hline $0.10 w t \%$ MSNP & 206 & 12 & 0.67 & 0.07 & 0.033 & 0.013 & 190 & 3 \\
\hline $0.20 \mathrm{wt} \% \mathrm{MSNP}$ & 188 & 1 & 0.41 & 0.00 & 0.024 & 0.006 & 178 & 3 \\
\hline
\end{tabular}


For the reciprocating friction tests, the results show a reduction of wear area of $19 \%$, and $22 \%$ for the $0.10 \mathrm{wt} \%$ and $0.20 \mathrm{wt} \%$ of GNP, respectively. The reduction in the wear area was $13 \%$ for the $0.20 \mathrm{wt} \%$ MSNP formulated oils. However, an increase of the wear has been recorded for the lower mass fractions of GNP and of MSNP (Figure 7). As for the wear produced on the chrome steel balls, the results are consistent with those obtained on the counter-pairs. A reduction in the wear track width is observed for the nanolubricants with the highest nanoparticle concentrations with both nano additive, as can be seen from Figure 8, there are reductions of $7 \%$ and $2 \%$ for $0.20 \mathrm{wt} \%$ of GNP and of MSNP were obtained, respectively. In order to identify the different mechanisms that take place during sliding wear, the worn plate was observed under a scanning electron microscope. Figure 9 shows optical and SEM images and wear morphology of the wear tracks for the stainless steel plates lubricated with neat oil (5W-30) and with nanolubricants. 


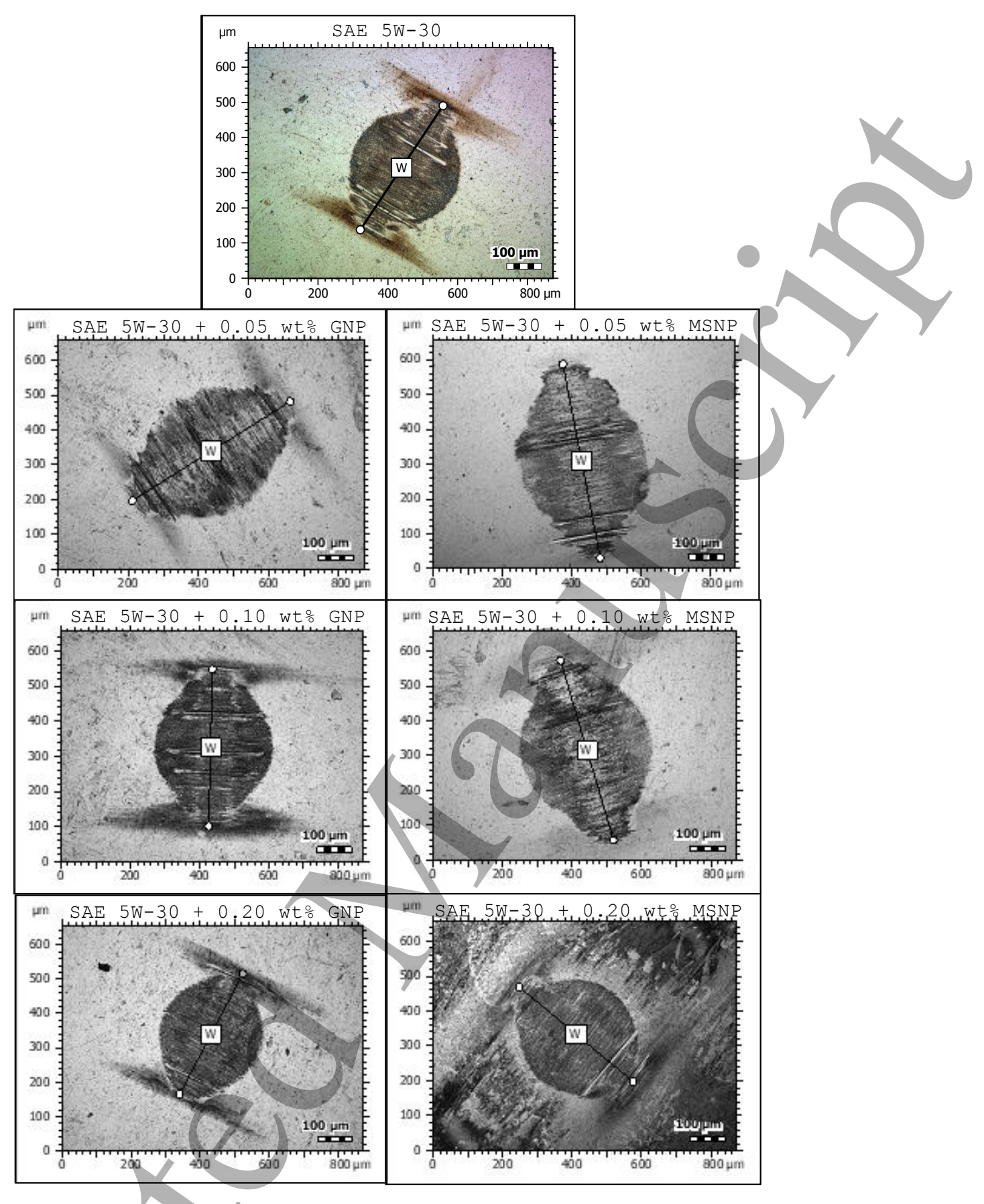

Figure 8. Optical images with the WTW of the wear scars on the chrome steel balls for the engine oil and the six different nanolubricants for the reciprocating friction tests. 
SAE $5 \mathrm{~W}-30$
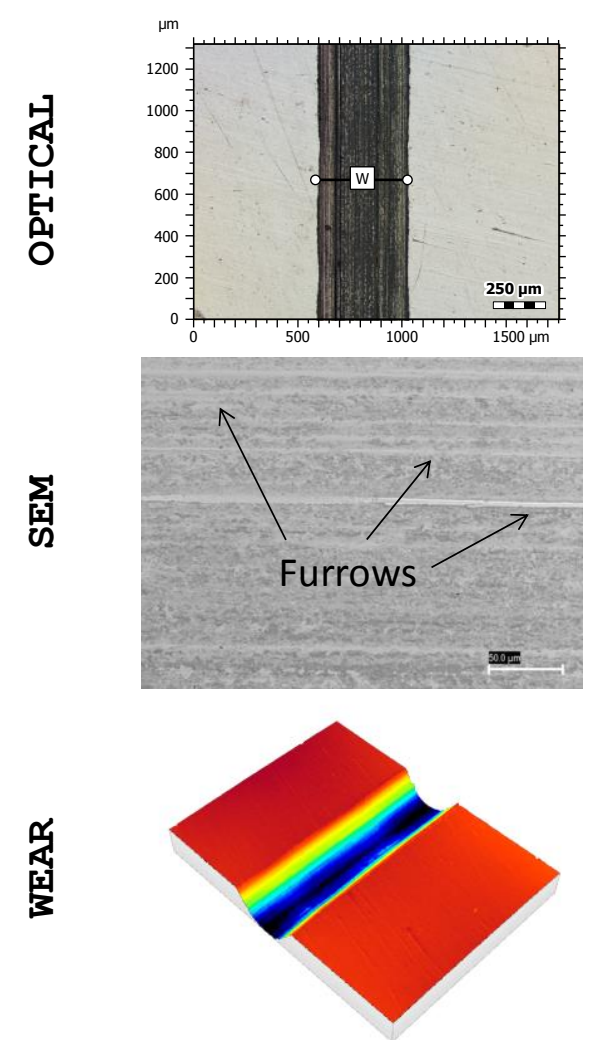

瓷
$0.20 w t \div G N P / 5 W-30$
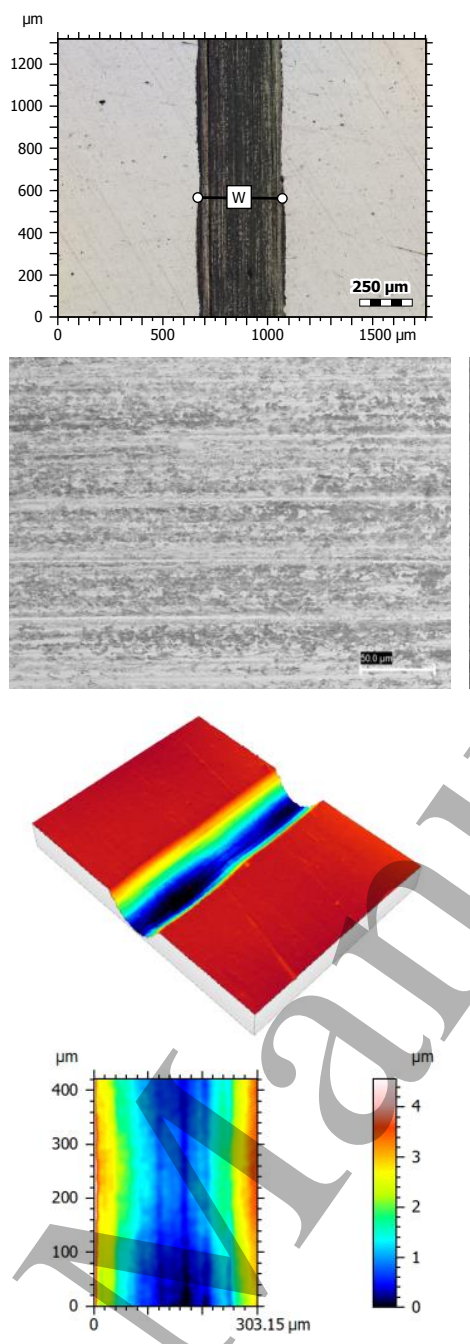

$0.20 \mathrm{wt} \div \mathrm{MSNP} / 5 \mathrm{~W}-30$
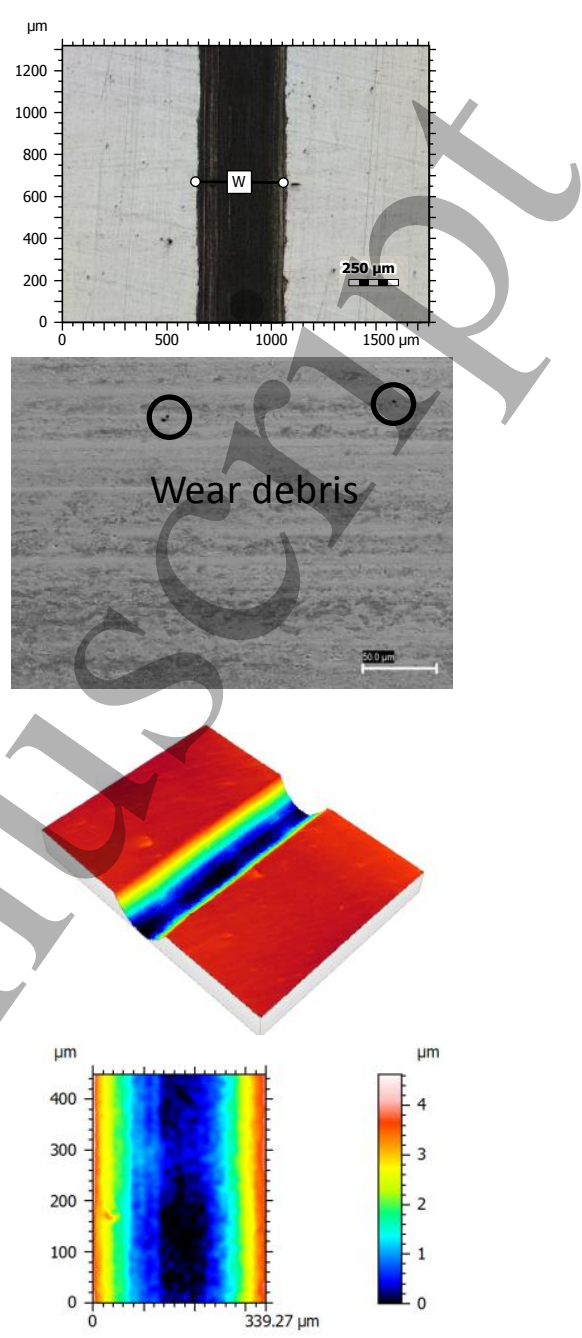

Figure 9. Optical and SEM images and wear and roughness map of the wear scars on the stainless steel plates for the engine oil and the best anti-wear nanolubricant concentration of each nano additive.

The oil doped with high GNP and MSNP loading showed the best anti-wear properties. Plastic deformation is evidenced in all the worn surfaces, with a deep welldefined scar. The furrows on the wear surface lubricated only with the engine oil is rougher and deeper, and larger number of furrow can be observed. These grooves are parallel to the ball sliding direction and the growth of subsurface grooves that cause the final detachment, which is a typical feature of abrasion wear. These furrows are smoother in the wear track of the specimens when the nanoplatelets were used as additives. The improvement in the 
antifriction properties of the lubricant after doping can be attributed to the multifunctional role of the nano additives. First, the 2D nature of the GNP and MSNP allow them to enter the frictional contact area, and the relative motion of the surfaces causes the nanoparticle to shear and adsorb some of the friction force. Second, the planner nature of GNP and MSNP allow them to be adsorbed readily on the surfaces and form protective friction films at the beginning of the loading. This protective film breaks with the contentious loading, and the big flakes fracture into smaller lateral diameter flakes that can easily be transferred with the lubricant flow. This transfer film provides farther protection by preventing, or minimising, the direct contact between two sliding surfaces. Furthermore, GNP and MSNP can mitigate any roughness present on the surface by filling the concave area and cover the roughness peaks, thereby help to form a uniform oil film and enhance the lubricity. It should be noted here that the 3D images show deeper and wider groves when the oil is doped with MSNP than with graphene. Due to the higher surface energy of graphene, graphene adsorbed onto the surface of the friction pair easier than MSNP, and hence it forms a more homogeneous physical protective film.

For the nanolubricant with $0.20 \mathrm{wt} \% \mathrm{MSNP}$, it is possible to detect some wear debris on the wear scar. Wear debris is typical of abrasive wear, which often occurs between soft surfaces and hard asperities. Furthermore, the roughness of the surface was also determined for the specimens lubricated with the doped and undoped oil (table 3). The value of $R_{a}$ in the wear scars is lower for the nanolubricants with $0.10 \mathrm{wt} \%, 0.20 \mathrm{wt} \%$ of GNP and for 0.20 wt $\%$ of MSNP with respect to undoped 5W-30 engine oil. This reduction in the roughness is in agreement with anti-wear behaviour results. The roughness reduction of the lubricating surface can be explained by nanoparticle-assisted abrasion, which is known as the polishing effect. The detection of the debris on the surface when the MSNP was used provides evidence for the polishing phenomenon. However, the increment 
of the $R_{a}$ in the nanolubricants with low concentrations (0.05 wt $\%$ of GNP and MSNP) is probably because of the lack of sufficient amounts of nano additives to produce an effective polishing. This fact explains the detrimental effect observed in the wear analysis for nanolubricants concentrations with low nanoparticles loading.

The average wear track width, WTW, produced by rotational friction test at 363.15 $\mathrm{K}$ on the chrome steel pins was represented in Figure S2 (supplementary information)/The doped oils showed excellent anti-wear behaviour for all concentrations tested. The best anti-wear performance was observed for the nanolubricant containing 0.05 wt $\%$ of MSNP with a corresponding WTW reduction of $42 \%$. The optical images of the wear scars on the chrome steel balls and on the pins for the engine oil and nanolubricants are shown in Figure S3 (supplementary information). The reduction in the width of the wear pattern has been greater on the pins than on the balls. For instance, for the $0.20 \mathrm{wt} \% \mathrm{GNP} / 5 \mathrm{~W}-30$ the WTW reduction was of $38 \%$ and $7 \%$ for the pin and the ball, respectively. This is a surprising result, considering the hardness of balls is higher than that of the pins. However, the planner morphology of the 2D materials, GNP and MSNP, allows them to attached better on the flat surface of the pins, unlike the curved ball. To gain more insights on the wear mechanism, roughness surface analysis was carried out to analyse the worn surface of the lubricated pins during the rotational friction tests. The results (Table 4) show a decrease in $R a$ when GNP and MSNP are used as additives compared to that obtained with undoped engine oil. An apparent polishing effect produced by the nanoparticles is again confirmed. The wear mechanism of $2 \mathrm{D}$ nanostructures materials additives helps to form a tribofilm and to sand the existing asperities on the contact surfaces, due to the exfoliation occurs between the adjacent layers under the applied shear stress [1]. Therefore, it can be concluded that the deposition of nanoparticles on the worn surface can decrease the shearing stress, and hence reduce friction and wear. The results of the unique tribological 
properties reveal that the GNP and MSNP obtained from a novel method are a promising additive for commercialisation of engine lubricants.

\section{CONCLUSIONS}

This work focuses on the thermophysical and tribological behaviour of doping engine lubricants with electrochemically exfoliated graphene and molybdenum disulfide nanoplatelets. The effect of the electrochemically exfoliated GNP and MSNP on the wettability of the engine base oil showed a decrease but without compromising its tribological performance. Moreover, unlike most reported nanolubricants, the GNP and MSNP doped oil showed decreases in kinematic viscosity and density due to the lack of aggregation of the nanoparticles. Further, for most formulated nanolubricants, a significant increase in the viscosity index was obtained. The antifriction behaviour for both nano additives obtained from a novel method was revealed for all the concentrations studied compared to the neat engine oil for both contact configurations. A maximum reduction of $20 \%$ was reached for the concentration of $0.10 \mathrm{wt} \% \mathrm{GNP} / 5 \mathrm{~W}-30$ in the reciprocating configuration tests. Besides, the addition of GNP and of MSNP in the 5W-30 engine oil showed excellent anti-wear properties, in particular for the ball-on-three-pins configuration. The rotational frictional tests lead to a decrease in the worn scar width of 38 and $42 \%$ for $0.20 \mathrm{wt} \% \mathrm{GNP} / 5 \mathrm{~W}-30$ and for $0.05 \mathrm{wt} \% \mathrm{MSNP} / 5 \mathrm{~W}-30$, respectively, compared to the neat oil. This excellent tribological behaviour in the boundary lubrication regime can be explained by two different nanoparticle mechanism detected during surface analyses when nano additives at an optimum concentration level are added to the base oil: film formation and polishing effect. Therefore, 2D nanomaterials obtained from a novel method were proposed as lubricant additives, which can help in the development of new lubrication systems with an excellent tribological performance for industrial applications. 
Finally, authors would like to note as future work the interest in studying the coefficient of friction variation and anti-wear mechanism of these nano additives in mixed lubrication regime in order to complete the tribological characterisation, because the lubrication mechanisms of the nano additives mentioned above take place especially under mixed and boundary lubrication. To this aim, it would be very advantageous to increase the stability of the nano additives studied in the base lubricant. One of the most effective ways to improve the nanolubricant stability is to use some dispersant, such as oleylamine or ascorbic acid.

\section{Nomenclature}

GNP Graphene nanoplatelets

MSNP Molybdenum disulfide nanoplatelets

SEM Scanning Electron Microscopy

FMs Friction Modifiers

FTIR Fourier Transform Infrared

PAO Polyalphaolefin

$n \quad$ Refractive index

$\theta \quad$ Average contact angle $\left(^{\circ}\right)$

$k \quad$ Coverage factor

$T \quad$ Temperature (K)

$\rho \quad$ Density $\left(\mathrm{g} \cdot \mathrm{cm}^{-3}\right)$

$\eta \quad$ Dynamic viscosity (Pa.s)

VI Viscosity index (-)

$\lambda \quad$ Specific film thickness (-)

$h_{\min } \quad$ Minimum lubricant film thickness (m)

$R_{a} \quad$ Roughness ( $\left.\mu \mathrm{m}\right)$

$R \quad$ Equivalent radius (m)

$U$ Dimensionless speed parameter

$G$ Dimensionless material parameter

W Dimensionless load parameter 


$$
\begin{array}{ll}
K & \text { Ellipticity parameter } \\
\alpha & \text { Pressure-viscosity coefficient } \\
F & \text { Normal load }(\mathrm{N}) \\
u & \text { Surface velocity }\left(\mathrm{m} \mathrm{s}^{-1}\right) \\
E^{*} & \text { Effective Young's modulus }(\mathrm{Pa}) \\
v & \text { Poisson's ratio } \\
F_{N} & \text { Normal tribological force } \\
\text { WTW } & \text { Wear track width }(\mu \mathrm{m}) \\
\text { WTD } & \text { Wear track depth }(\mu \mathrm{m}) \\
\sigma & \text { Standard deviation of the mean } \\
v & \text { Kinematic viscosity }\left(\mathrm{mm}^{2} \cdot \mathrm{s}^{-1}\right) \\
\text { COF } & \text { Coefficient of friction }(-) \\
\text { Subscripts } \\
1=\text { ball } \\
2=\text { plate or pin } \\
\mathrm{x}, \mathrm{y}=\text { coordinates system }
\end{array}
$$

Notes. Authors declare no competing financial interest.

\section{ACKNOWLEDGMENTS}

Authors thank to Dr. Alfredo Amigo (from Department of Applied Physics, University of Santiago de Compostela) for the useful assistance with the contact angle analyser and for kindly allowing the use of the refractometer. This work was supported by both the Spanish Ministry of Economy and Competitiveness (MINECO) and the ERDF programme through ENE2017-86425- C2-2-R project, and by the Xunta de Galicia (AEMAT ED431E 2018/08 and GRC ED431C 2016/001). These funders also financed the acquisition of the 3D Optical Profile (UNST15-DE-3156). Dr. María J. G. Guimarey acknowledges a postdoctoral fellowship from the Xunta de Galicia (Spain). 


\section{REFERENCES}

1. Srivyas P, Charoo MS. 2018 Tribol Ind 40 594-623.

2. Erdemir A, Holmberg K. 2015 Energy Consumption Due to Friction in Motored Vehicles and Low-Friction Coatings to Reduce It. Coating Technology for Vehicle Applications ed Cha SC, Erdemir A: Springer Verlag, Heidelberg) p. 1-24

3. Holmberg K, Erdemir A. 2017 Friction 5 263-284.

4. Holmberg K, Andersson P, Erdemir A. 2012 Tribol Int 47 221-234.

5. Roberts A, Brooks R, Shipway P. 2014 Energ Convers Manage 82 327-350.

6. Tzanakis I, Hadfield M, Thomas B, Noya SM, Henshaw I, Austen S. 2012 Renew Sust Energ Rev 16 4126-4140.

7. $\quad$ Tung SC, McMillan ML. 2004 Tribol Int 37 517-536.

8. Tang Z, Li S. 2014 Curr Opin Solid State Mater Sci 18 119-139.

9. Ali MKA, Xianjun H, Turkson RF, Peng Z, Chen X. 2016 RSC Adv 6 7791377924.

10. Li B, Wang X, Liu W, Xue Q. 2006 Tribol Lett, 22 79-84.

11. Wang X-B, Liu W-M. 2013 Nanoparticle-Based Lubricant Additives. Encyclopedia of Tribology ed Wang QJ, Chung Y-W (Boston, MA: Springer US) p. 2369-2376

12. Ahmed Ali M, Hou X, Turkson R, Peng Z, Chen X. 2016 RSC Adv 6 77913-77924.

13. Hamrock BJ, Dowson D. 1982 J Lubr Technol 104 279-281.

14. Dinesh R, Prasad MJG, Kumar RR, Santharaj NJ, Santhip J, Raaj ASA. 2016 Mater Today: Proc 3 45-53.

15. Kasai T, Bhushan B, Kulik G, Barbieri L, Hoffmann P. 2005 J Vac Sci Technol B 23 995-1003.

16. Pham DC, Na K, Piao S, Cho IJ, Jhang KY, Yoon ES. 2011 Nanotechnol 22 395303.

17. Dai W, Kheireddin B, Gao H, Liang H. 2016 Tribol Int 102 88-98.

18. Eswaraiah V, Sankaranarayanan V, Ramaprabhu S. 2011 ACS Appl Mater Interfaces 3 4221-4227.

19. Lin J, Wang L, Chen G. 2011 Tribol Lett 41 209-215.

20. Kogovšek J, Kalin M. 2014 Tribol Lett 53 585-597.

21. Koshy CP, Rajendrakumar PK, Thottackkad MV. 2015 Wear 330-331 288-308.

22. Abdelkader AM, Kinloch IA, Dryfe RA. 2014 ACS Appl Mater Interfaces 6 16321639. 
23. Smith B. 2015 Spectrosc 30 40-46.

24. Guimarey MJG, Comuñas MJP, López ER, Amigo A, Fernández J. 2019 J Chem Thermodyn 131 192-205.

25. Farsadi M, Bagheri S, Ismail NA. 2017 J Mol Liq 244 304-308.

26. Guo Y-B, Zhang S-W. 2016 Lubricants 430.

27. Gupta B, Kumar N, Panda K, Dash S, Tyagi AK. 2016 Sci Rep 618372.

28. Guimarey MJG, Salgado MR, Comuñas MJP, López ER, Amigo A, Cabaleiro D, et al. 2018 J Mol Liq 262 126-138.

29. Gaciño FM, Regueira T, Lugo L, Comuñas MJP, Fernández J. 2011 J Chem Eng Data 56 4984-4999.

30. ASTM D2270 Standard Practice for Calculating Viscosity Index from Kinematic Viscosity at 40 and $100^{\circ} \mathrm{C},(2016)$.

31. Minami I, Inada T, Sasaki R, Nanao H. 2010 Tribol Lett 40 225-235.

32. Heyer P, Läuger J. 2009 Lubr Sci 21 253-268.

33. Nasser KI, Liñeira del Río JM, López ER, Fernández J. 2020 J Mol Liq 113343.

34. Kalin M, Polajnar M. 2013 Tribol Int 66 225-233.

35. Kozbial A, Gong X, Liu H, Li L. 2015 Langmuir 31 8429-8435.

36. Rasheed AK, Khalid M, Rashmi W, Gupta TCSM, Chan A. 2016 Renew Sustain Energy Rev 63 346-362.

37. Azman SSN, Zulkifli NWM, Masjuki H, Gulzar M, Zahid R. 2016 J Mater Res 31 1932-1938.

38. Kotia A, Borkakoti S, Ghosh SK. 2018 Particuology 37 54-63.

39. Abdelkader AM, Kinloch I. 2016 ACS Sustainable Chem Eng 4 4465-4472.

40. Abdelkader AM, Patten HV, Li Z, Chen Y, Kinloch IA. 2015 Nanoscale $711386-$ 11392.

41. Vattikuti SVP, Byon C. 2015 J Nanomat 2015710462.

42. Ahmadi Nadooshan A, Hemmat Esfe M, Afrand M. 2017 Physica E: Low Dimens Syst Nanostruc 92 47-54.

43. Alasli A, Evgin T, Turgut A. 2018 Colloids Surf A 538 219-228.

44. Ali MKA, Xianjun H, Mai L, Qingping C, Turkson RF, Bicheng C. 2016 Tribol Int $103540-554$.

45. Ettefaghi E-o-1, Ahmadi H, Rashidi A, Nouralishahi A, Mohtasebi SS. 2013 Int Commun Heat Mass Transfer 46 142-147. 
46. Wong VW, Tung SC. 2016 Friction 4 1-28.

47. Paul G, Hirani H, Kuila T, Murmu NC. 2019 Nanoscale 11 3458-3483. 